\title{
PENGARUH PENERAPAN KURIKULUM KHAS TERHADAP PEMBENTUKAN KARAKTER SISWA DI SDIT PERMATA BUNDA
}

\author{
Evy Rukhayati 1) * \\ Ahmad Muflihin 2) \\ ${ }^{1}$ Program Studi Pendidikan Agama Islam, Fakultas Agama Islam \\ Universitas Islam Sultan Agung, Semarang \\ 2 Program Studi Pendidikan Agama Islam, Fakultas Agama Islam \\ Universitas Sultan Agung, Semarang \\ *E-mail: evyrukhayati@std.unissula.ac.id
}

\begin{abstract}
The Integrated Islamic Schools Network (JSIT) applies a typical curriculum for Integrated Islamic Schools (SIT) to shape student character in accordance with the Quran and Sunnah. A typical curriculum is a curriculum that is applied and becomes a special feature of SIT, national curriculum development but is expanded and deepened by JSIT Indonesia and independent. This typical curriculum is applied with the aim of dealing with moral aspects that are often overlooked in the education process. This article aims to determine the effect of applying a typical curriculum to the formation of student character at SDIT Permata Bunda. This research is field research with quantitative methods using a questionnaire. The results showed that the calculated $r$-value of 0.119 was smaller than the r-value of table 0.220. So, it can be concluded that there is no influence between the application of a typical curriculum to the formation of student character at SDIT Permata Bunda. Therefore, there are several things that need to be evaluated so that the application of this typical curriculum can run more optimally.
\end{abstract}

Keywords: Typical Curriculum, Formation of Student Character

\begin{abstract}
Abstrak
Abstrak: Jaringan Sekolah Islam Terpadu (JSIT) menerapkan kurikulum khas pada Sekolah Islam Terpadu (SIT) guna membentuk karakter siswa yang sesuai dengan al-Qur'an dan as-Sunnah. Kurikulum khas merupakan kurikulum yang diterapkan dan menjadi kekhasan SIT, pengembangan dari kurikulum nasional namun diperluas dan diperdalam oleh JSIT Indonesia dan bersifat mandiri. Kurikulum khas ini diterapkan dengan tujuan untuk menangani aspek moralitas yang seringkali terabaikan dalam proses pendidikan. Artikel ini bertujuan untuk mengetahui pengaruh penerapan kurikulum khas terhadap pembentukan karakter siswa di SDIT Permata Bunda. Penelitian ini merupakan penelitian lapangan dengan metode kuantitatif menggunakan kuesioner (angket). Hasil penelitian menunjukkan bahwa nilai $r$ hitung sebesar 0,119 lebih kecil dibandingkan nilai $r$ tabel sebesar 0,220. Sehingga, dapat disimpulkan bahwa tidak ada pengaruh antara penerapan kurikulum khas terhadap pembentukan karakter siswa di SDIT Permata Bunda. Oleh karena itu, ada beberapa hal yang perlu dievaluasi agar penerapan kurikulum khas ini dapat berjalan lebih optimal.
\end{abstract}

Kata Kunci: Kurikulum Khas, Pembentukan Karakter Siswa

\section{PENDAHULUAN}

Pada dasarnya setiap manusia memiliki karakter sesuai dengan fitrahnya masingmasing. Akan tetapi dalam proses kehidupannya karakter tersebut dapat dibentuk dan dikembangkan melalui proses pendidikan. Pendidikan karakter merupakan upaya untuk 
membantu perkembangan jiwa anak-anak baik lahir mapun batin, dari sifat kodratinya menuju ke arah peradaban yang manusiawi dan lebih baik. Pendidikan karakter merupakan proses yang berkelanjutan dan tak pernah berakhir, sehingga menghasilkan perbaikan kualitas yang berkesinambungan yang ditujukan pada terwujudnya sosok generasi masa depan.

Perkembangan globalisasi merupakan sebuah keniscayaan yang tidak bisa dihindari. Segala bentuk arus informasi dapat diterima tanpa batas tanpa sekat meskipun berbeda negera. Hal tersebut tentu memudahkan setiap orang untuk kapanpun dan di manapun. Namun, di sisi yang lain, apabila laju globalisasi ini tidak dapat dikendalikan, maka setiap bangsa akan kehilangan jati dirinya.

Krisis moralitas marak terjadi belakangan ini, seperti tawuran antar pelajar, seks bebas, kasus video porno, penggunaan narkotika, dan berbagai macam kasus serupa salah satunya dikarenakan dunia pendidikan masih menitikberatkan dalam hal kognitif dan kurang memerhatikan dari aspek akhlak dan budi pekerti siswa.

Jadi bisa dikatakan bahwa penyebab terbesar dalam krisis pendidikan ini adalah gagalnya pembangunan karakter anak didik. Kegagalan ini terjadi karena aspek akhlak atau moralitas terabaikan dalam proses pendidikan yang sedang berlangsung (Amri Syafri, 2012).

Hal ini tentu tidak sesuai dengan tujuan pendidikan dalam Undang-Undang Nomor 20 tahun 2003 tentang Sistem Pendidikan Nasional, pasal 3, tujuan pendidikan nasional adalah mengembangkan potensi peserta didik agar menjadi manusia yang beriman dan bertakwa kepada Tuhan Yang Maha Esa, berakhlak mulia, sehat, berilmu, cakap, kreatif, mandiri, dan menjadi warga negara yang demokratis serta bertanggung jawab. Sesuai dengan hal tersebut bahwa tujuan pendidikan nasional adalah untuk melahirkan manusia yang beriman dan bertakwa. Dalam pasal 36 tentang kurikulum dikatakan, kurikulum disusun dengan memerhatikan peningkatan iman dan takwa.

Oleh karena itu Jaringan Sekolah Islam Terpadu (JSIT) mencoba memberikan kurikulum tambahan atau nilai-nilai tambahan dalam Sekolah Islam Terpadu (SIT) guna membentuk karakter siswa yang sesuai dengan ajaran Islam, yaitu al-Qu'ran dan asSunah.

Dalam artikel ini akan dipaparkan hasil penelitian tentang pengaruh penerapan kurikulum khas terhadap pembentukan karakter siswa di SDIT Permata Bunda. 


\section{METODE}

Jenis penelitian ini adalah penelitian lapangan (field research) dengan pendekatan kuantitatif. Teknik pengumpulan data yang digunakan dalam memperoleh data yaitu dengan menggunakan angket atau kuesioner. Penulis menggunakan kuesioner model skala ordinal (Likert) di mana di dalamnya terdapat beberapa kategori yang disimbolkan dengan angka, angka 4 untuk selalu, angka 3 untuk sering, angka 2 untuk jarang, dan angka 1 untuk tidak pernah. Intrumen tersebut diuji validitas dan reliabilitasnya sebelum digunakan.

Dalam penelitian ini ada dua variabel, yaitu variabel kurikulum khas dan variabel karakter. Indikator yang dijadikan pernyataan kuesioner dari variabel kurikulum khas program BIAS yaitu: proses islamisasi dalam proses pembelajaran dan kemitraan antar beberapa pihak terkait. Sedangkan dari variabel karakter yaitu nilai religious, jujur, tekun, disiplin, dan tanggung jawab. Dari berbagai indikator tersebut kemudian dibuatlah butirbutir pernyataan dalam bentuk kuesioner.

Dalam hal pengujian validitas instrumen atau kuesioner dilakukan dengan rumus sebagai berikut : (Sugiyono, 2012)

$$
r=\frac{n \sum x y-\left(\sum x\right)\left(\sum y\right)}{\sqrt{\left(\mathrm{n} \sum x^{2}-\left(\sum x\right)^{2}\right)\left(\mathrm{n} \sum y^{2}-\left(\left(\sum y\right)^{2}\right)\right)}}
$$

Setelahnya kemudian dilakukan uji reliabilitas yang bertujuan untuk menunjukkan sejauh mana instrumen yang digunakan dapat dipercaya (Sugiyono, 2016). Teknik yang digunakan yaitu menggunakan rumus koefisien Cronbach's Alpha yaitu :

$$
r_{11}=\left[\frac{k}{k-1}\right]\left[1 \frac{\Sigma S_{i}^{2}}{\Sigma S_{t}^{2}}\right]
$$

Keterangan:

$r_{11}=$ Reliabilitas yang dicari

$k \quad=$ Banyaknya butir tes

$\Sigma S_{i}^{2}=$ Skor total varian butir

$\Sigma S_{t}^{2}=$ Skor varian total

Hasil ujinya apabila nilai Cronbach's Alpha lebih besar dari r tabel maka instrumen kuesioner dinyatakan reliabel. Kemudian sumber data dalam penelitian ini ada dua, yaitu sumber data primer dan data sekunder. Data primer didapatkan dari jawaban kuesioner yang diberikan kepada guru dan siswa. Sedangkan data sekunder berasal dari dokumen- 
dokumen pendukung dalam pengimplementasian kurikulum khas tersebut, seperti RPP dan lain-lain.

Adapun yang menjadi populasi dalam penelitian ini adalah siswa kelas IV-VI SDIT Permata Bunda yang berjumlah 360 siswa serta seluruh guru di SDIT Permata Bunda yang berjumlah 55 orang. Hal ini dikarenakan siswa kelas IV-VI sudah menerima kurikulum khas secara keseluruhan.

Mengingat jumlah subyek yang diteliti lebih dari 100 orang untuk siswa, maka penulis mengambil sampel dengan menggunakan rumus Slovin dengan rumus: $n=N /$ $\left(1+\mathrm{Ne}^{\wedge} 2\right)$. Berdasarkan rumus tersebut didapatkan hasil sampel sebanyak 78,2 orang (yang terletak pada rentang 21-22\%) yang kemudian dilipatkan menjadi 78 orang siswa yang diambil secara acak (random) dari kelas IV-VI SDIT Permata Bunda. Sedangkan untuk sampel terhadap guru SDIT Permata Bunda, sampel diambil keseluruhan dari populasi guru yang berjumlah 55 orang dikarenakan jumlahnya tidak lebih dari 100 orang, sesuai dengan pendapat Suharsimi Arikunto.

Dalam mengolah data, untuk mengetahui presentase hasil dari angket responden digunakan rumus:

$$
\%=\frac{\mathrm{n}}{\mathrm{N}} \times 100 \%
$$

Keterangan:

$\%=$ Presentase yang dicari

$\mathrm{N} \quad=$ Nilai yang diperoleh

$\mathrm{N}=$ Jumlah seluruh nilai

Berikut merupakan tabel tentang presentase deskripsi:

\begin{tabular}{|l|l|}
\hline $\begin{array}{l}\text { Rentang } \\
\text { Presentase }\end{array}$ & Kualitas \\
\hline $\mathrm{X} \geq \mathrm{M}+\mathrm{SD}$ & Baik \\
\hline $\begin{array}{l}\mathrm{M}-\mathrm{SD} \leq \mathrm{X}< \\
\mathrm{M}+\mathrm{SD}\end{array}$ & Cukup \\
\hline $\mathrm{X}<\mathrm{M}-\mathrm{SD}$ & Rendah/kurang \\
\hline \multicolumn{2}{|c|}{ (Azwar, 2012) } \\
\hline
\end{tabular}


Data yang didapatkan dari hasil kuesioner juga diolah menggunakan aplikasi SPSS dengan rumus Product Moment (PPMC):

$$
r_{x y}=\frac{n(\Sigma X Y)-(\Sigma X)(\Sigma Y)}{\sqrt{\left.\left[n \sum x^{2}-(\Sigma X)^{2}\right)\right]\left[\left(n \Sigma Y^{2}-(\Sigma Y)^{2}\right]\right.}}
$$

Keterangan:

$$
\begin{array}{ll}
\mathrm{rxy} & =\text { koefisien korelasi } \\
\mathrm{n} & =\text { jumlah sampel } \\
\mathrm{x} & =\text { Variabel } \mathrm{x} \\
\mathrm{y} & =\text { Variabel } \mathrm{y}
\end{array}
$$

\section{HASIL DAN PEMBAHASAN}

Berdasarkan hasil analisis uji hipotesis dengan teknik korelasi product moment menggunakan SPSS 16 disimpulkan bahwa nilai $r$ hitung $(0,119)$ lebih kecil dari nilai $r$ tabel $(0,220)$. Sehingga Ha ditolak dan Ho diterima, yang berarti bahwa tidak ada pengaruh antara penerapan kurikulum khas terhadap pembentukan karakter siswa di SDIT Permata Bunda. Tidak adanya pengaruh antara penerapan kurikulum khas terhadap pembentukan karakter siswa di SDIT Permata Bunda dalam penelitian ini disebabkan beberapa hal, yaitu:

a. Hasil dari kuesioner menyatakan bahwa pelaksanaan kurikulum khas dan pembentukan karakter siswa di SDIT Permata Bunda mendapatkan hasil yang cukup, yaitu sebesar 96,15\% untuk penerapan kurikulum khas dan 67,95\% untuk pembentukan karakter siswa.

b. Dari analisis item pernyataan, didapatkan hasil bahwa item pernyataan nomor 3 dari kuesioner penerapan kurikulum khas hanya memperoleh hasil sebesar 20,51\% untuk jawaban selalu. Jika dibandingkan dengan item pernyataan lain yang memperoleh hasil berkisar 50\%, item pernyataan ini memiliki selisih hasil yang cukup besar.

c. Dari analisis item pernyataan, didapatkan hasil bahwa item pernyataan nomor 9 dari kuesioner penerapan kurikulum khas hanya memperoleh hasil sebesar 28,21 \% untuk jawaban selalu. Jika dibandingkan dengan item pernyataan lain yang memperoleh hasil berkisar 50\%, item pernyataan ini memiliki selisih hasil yang cukup besar.

d. Dari analisis item pernyataan, didapatkan hasil bahwa item pernyataan nomor 5 dari kuesioner pembentukan karakter siswa hanya memperoleh hasil sebesar 17,95\% untuk jawaban selalu. Jika dibandingkan dengan item pernyataan lain yang 
44 | Evy Rukhayati \& Ahmad Muflihin

memperoleh hasil berkisar 50\% hingga 60\%, item pernyataan ini memiliki selisih hasil yang cukup besar.

e. Dari analisis item pernyataan, didapatkan hasil bahwa item pernyataan nomor 9 dari kuesioner pembentukan karakter siswa hanya memperoleh hasil sebesar 21,79\% untuk jawaban selalu. Jika dibandingkan dengan item pernyataan lain yang memperoleh hasil berkisar 50\% hingga 60\%, item pernyataan ini memiliki selisih hasil yang cukup besar.

f. Dari analisis item pernyataan, didapatkan hasil bahwa item pernyataan nomor 13 dari kuesioner pembentukan karakter siswa hanya memperoleh hasil sebesar 29,49\% untuk jawaban selalu. Jika dibandingkan dengan item pernyataan lain yang memperoleh hasil berkisar 50\% hingga 60\%, item pernyataan ini memiliki selisih hasil yang cukup besar.

g. Dari analisis item pernyataan, didapatkan hasil bahwa item pernyataan nomor 17 dari kuesioner pembentukan karakter siswa hanya memperoleh hasil sebesar 21,79\% untuk jawaban selalu. Jika dibandingkan dengan item pernyataan lain yang memperoleh hasil berkisar 50\% hingga 60\%, item pernyataan ini memiliki selisih hasil yang cukup besar.

\section{SIMPULAN DAN SARAN}

\section{Simpulan}

Penerapan kurikulum khas di SDIT Permata Bunda mendapatkan kategori cukup dengan perolehan hasil sebesar 96,15\% dari 78 responden. Sedangkan untuk pembentukan karakter siswa di SDIT Permata Bunda mendapatkan kategori cukup dengan perolehan hasil sebesar 67,95\% dari 78 responden. Dari hasil penelitian didapatkan bahwa tidak ada pengaruh antara penerapan kurikulum khas terhadap pembentukan karakter siswa di SDIT Permata Bunda dikarenakan nilai r hitung $(0,119)$ lebih kecil dari $r$ tabel $(0,220)$. Hal ini disebakan karena siswa belum sepenuhnya mengikuti atau menerapkan kurikulum khas. Oleh karena itu, ada beberapa hal yang perlu dievaluasi agar penerapan kurikulum khas ini dapat berjalan lebih optimal.

\section{Saran}

Diharapkan guru dapat menerapkan kurikulum khas dengan lebih baik lagi sehingga tercipta pembentukan karakter sesuai dengan yang diharapkan. Kemudian para siswa dapat menerapkan ajaran-ajaran yang telah dipelajari dan diperoleh di sekolah dengan lebih baik sehingga dapat tercipta pembentukan karakter sesuai dengan yang diharapkan. 
Serta sekolah dapat mendukung pihak guru dalam menerapkan kurikulum khas sehingga dapat tercipta pembentukan karakter sesuai dengan yang diharapkan.

\section{DAFTAR PUSTAKA}

Agus, R. (2011). Buku Ajar Metodologi Penelitian. EGC.

Amri Syafri, U. (2012). Pendidikan Karakter Berbasis Al-Qur'an. PT RajaGrafindo Persada.

Azwar, S. (2012). Penyusunan Skala Psikologi (2nd ed.). Pustaka Pelajar.

Edy Susanto, M. (2019). Pendidikan Karakter Dalam Cerita Anak Berjudul Kecil Jadi Kawan, Besar Jadi Lawan Karya Tri Isyanti dan Siti Andari. Journal of Chemical Information and Modeling, 53(9), 1689-1699. https://doi.org/10.1017/CB09781107415324.004

Febrianshari, D., Kusuma, V. C., Jayanti, N. D., Ekowati, D. W., Prasetya, M. Y., \& Suwandayani, I. (2018). ANALISIS NILAI-NILAI PENDIDIKAN KARAKTER. 6(April), 88-95.

Gunawan, H. (2014). Pendidikan Islam Kajian Teoretis dan Pemikiran Tokoh. PT Remaja Rosdakarya.

Idi, A., \& Hd, S. (2015). Etika Pendidikan Keluarga, Sekolah, dan Masyarakat. PT RajaGrafindo Persada.

Indonesia, J. (2014). Standar Mutu Kekhasan Sekolah Islam Terpadu.

Mulyasa, E. (2011). Manajemen Pendidikan Karakter. Bumi Aksara.

Mustari, M. (2014). Nilai Karakter Refleksi Untuk Pendidikan. PT RajaGrafindo Persada.

Nurul Hidayah. (2015). Penanaman Nilai-nilai Karakter dalam Pembelajaran Bahasa Indonesia di Sekolah Dasar. Jurnal Pendidikan Dan Pembelajaran Dasar, 2(2), 190204.

Pendidikan, L. (2019). Jurnal kependidikan. 7(1), 1-16.

Putry, R. (2018). Gender Equality: Internasional Journal of Child and Gender Studies ISSN: 2461-1468/E-ISSN: 2548-1959. Journal of Child and Gender Studies ISSN, 4(1), 3954.

Sugiyono. (2012). Statistika Untuk Penelitian. Alfabeta.

Sugiyono. (2016). Metode Penelitian Kualitatif, Kuantitatif dan R\&D. Alfabeta.

Supardi. (2017). Statistik Penelitian Pendidikan. Rajawali Pers.

Sutomo, Prihatin, T., \& Bayu Kusumandari, R. (2016). Manajemen Sekolah. UNNES Press. 
46 | Evy Rukhayati \& Ahmad Muflihin

Wibowo, A. (2013). Manajemen Pendidikan Karakter Di Sekolah. Pustaka Pelajar.

Yulianti, S. D., Djatmika, E. T., \& Susanto, A. (2016). Pendidikan Karakter Kerja Sama Dalam Pembelajaran Siswa Sekolah Dasar Pada Kurikulum 2013. Jurnal Teori Dan Praksis Pembelajaran IPS, 1(1), 33-38. https://doi.org/10.17977/um022v1i12016p033 